Reprod. Nutr. Dévelop., 1980, 20 (5 A), 1481-1488.

\title{
Variations of bile salt pool size and secretion rate in rats according to the modes of sterilization and preparation of a semi-synthetic diet
}

\author{
par M. RIOTTOT, E. SACQUET, C. LEPRINCE \\ Laboratoire des Animaux sans Germes du C.N.R.S. \\ C.N.R.Z.-I.N.R.A., 78350-Jouy-en-Josas, France.
}

\begin{abstract}
Summary. A semi-synthetic dief was sterilized by irradiation and given to rats as pellets, powder or paste obtained by admixing an equal amount of water. The bile salt pool increased from the first to the third treatment. That effect disappeared when the starch was replaced by sucrose or when the diet was autoclaved instead of irradiated. The bile duct secretion of bile salts varied according to the bile salt pool. Hypotheses are proposed to explain the relationship between the form of the diet and bile salt pool size and secretion.
\end{abstract}

\section{Infroduction.}

In a previous paper (Sacquet, Leprince and Riottot, 1979), it was shown that (i) axenic and holoxenic (conventional) rats fed a semi-synthetic diet had a larger bile salt (BS) pool and excreted less fecal BS when the diet was sterilized by irradiation than by autoclaving, and that (ii) adding 10 p. 100 of lactose to the diet had no effect in the first case but increased the BS pool in the second. However, the irradiated (I) and autoclaved $(\mathrm{Au})$ diets in that experiment were prepared differently, although their composition was the same. The I diet was given as a paste obtained by mixing equal weights of sterilized powder and water. The Au diet, only admixed with $200 \mathrm{~g}$ of water per $\mathrm{kg}$, was pressed prior to autoclaving and fed as pellets.

The purpose of the present study was to determine whether the previously observed variations in the BS pool were induced by the way in which the diet was sterilized or by the way in which it was prepared. In addition, we planned to observe how the bile duct secretion of bile salts varied according to the pool. We therefore used a new technique and tested its value.

\section{Material and methods.}

Experimental animals. - As previously, we used inbred male Fischer rats from our animal room. Only holoxenic (conventional) animals were used in this study. When 3 months old, they were given the experimental diet for 30 days prior to the experiment. 
Diets. - As previously, the basal diet included $200 \mathrm{~g}$ of casein, $580 \mathrm{~g}$ of maize starch, $90 \mathrm{~g}$ of maize oil, $50 \mathrm{~g}$ of cellulose, $45 \mathrm{~g}$ of a mineral mixture and vitamin in sufficient amounts. This powder diet was treated in 9 different ways which are designated as follows :

(1) St. Pel. Au. (starch, pelleted, autoclaved) diet; admixed with $200 \mathrm{~g}$ of water per $\mathrm{kg}$, pelleted and autoclaved at $120^{\circ} \mathrm{C}$ for $20 \mathrm{~min}$; called $\mathrm{Au}$ in the previous study ;

(2) St. L. Pel. Au. (starch, lactose, pelleted, autoclaved) diet ; admixed with 10 p. 100 of lactose and treated as in (1); called LAu in the previous study ;

(3) St. Pa. Au. (starch, paste, autoclaved) diet; admixed with an equal weight of water to make a paste and then autoclaved;

(4) St. Pel. I. (starch, pelleted, irradiated) diet ; pelleted, put into polyethylene bags, sealed under vacuum and irradiated ;

(5) St. Pw. I. (starch, powder, irradiated) diet; not pelleted but put as a powder into polyethylene bags, irradiated and then fed in that form ;

(6) St. Pa. I. (starch, paste, irradiated) diet ; treated as in (5), admixed with an equal weight of water to make a paste when fed ; previously called I ;

(7) St. L. Pa. I. diet ; admixed with 10 p. 100 of lactose and then treated as in (6); previously called $\mathrm{LI}$;

(8) and (9). The starch in these 2 diets was replaced by an equal weight of sucrose to obtain the Su. Pw. I. (sucrose, powder, irradiated) diet, treated as in (5), or the Su. Pa.I. diet after an equal weight of water was added as in (6) before being given to the rats.

Studies of bile acid metabolism. - Bile acid pool size and secretion were measured in acute bile fistula studies using the technique described by Mok, Perry and Dowling (1974) called the « washout » (WO) technique. The rats were not fasted. They were operated at 9 a.m. under a light ether anesthesia. The abdomen was opened, a polyethylene tube (OD : $0.70 \mathrm{~mm}, I D: 0.30 \mathrm{~mm}$ ) was inserted into the bile duct, the abdomen was closed and the rat was put into a Bollman restraining cage. Bile was collected at $90 \mathrm{~min}$ intervals for $24 \mathrm{hrs}$. Food and water were available to the rats during that time.

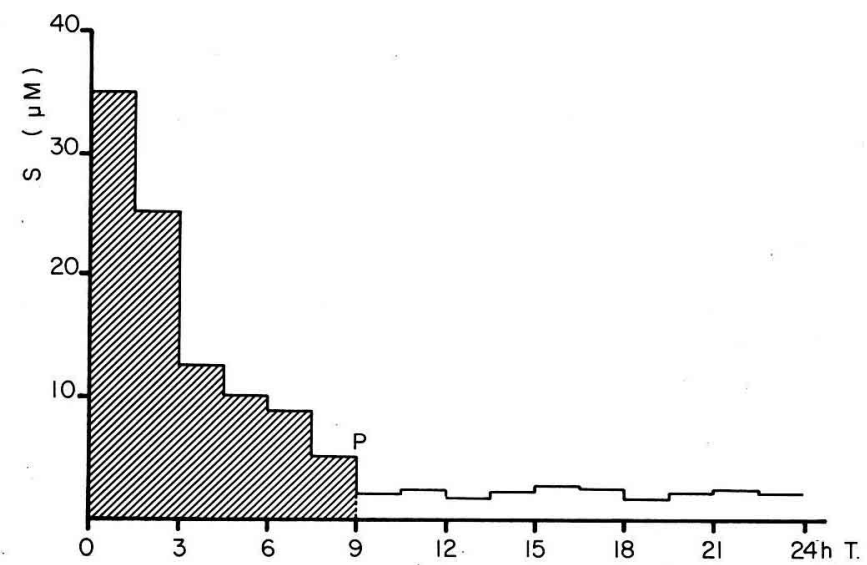

FIG. 1. - Amounts of bile salt collected by the "wash out 》 technique. Abscissa : time $T$ in hours after bile duct cannulation ; ordinate : $\mu$ moles of bile salt in each fraction (S). Fractions 1 to 6 (hatched area) arre considered as corresponding to pool (P). 
The amount of bile salts contained in each fraction was measured by 3-hydroxysteroid-dehydrogenase according to the technique of Stempfel and Sidbury (1964). Figure 1 gives an example of the bile salt secretion rate after cannulation of the bile duct ; the bile salt content of each fraction declined until fraction 5 or 6 was obtained, and then remained at a low level.

According to Mok, Perry and Dowling (1974), the amount of bile salts collected in the first fraction was used to calculate a 24-hour secretion rate. The amount of bile salts collected in the first 5 or 6 fractions, i.e. as long as the amount collected declined, was considered as the bile salt pool.

As the amount of bile salts collected during the terminal period remained at a plateau, according to Mok, Perry and Dowling, the values of the secretion rates observed during that period represented the « basal rate of hepatic bile acid synthesis 》; they calculated daily bile acid synthesis from those values.

A preliminary experiment was carried out to check the value of this hypothesis. ${ }^{14} \mathrm{C}$-cholesterol isotope equilibrium (CIE) was achieved in 7 rats fed a commercial diet, according to a previously described technique (Sacquet et al., 1975). Three of those rats were submitted to the WO technique. In addition, we measured the amount of radioactivity corresponding to the bile salt pool as well as the amount left in the intestine and excreted in the feces while the rats were restrained in Bollman cages. The bile salt pool and the fecal excretion of the other 4 rats were determined according to the routine CIE method. Moreover, the results obtained by the isotope method in conventional rats fed the I, LI, Au and LAu diets of the previous experiments (Sacquet, Leprince and Riottot, 1979) were compared to those obtained in the present study using the WO technique.

Statistical analysis. - The results are expressed by the arithmetic means and the standard deviation of the mean. The different groups were compared using a two-way variance analysis (Snedecor and Cochran, 1957).

\section{Results.}

Comparison of the WO and cholesterol isotope equilibrium techniques.

Very little radioactivity was excreted in the fecal bile salts of 3 rats in cholesterol isotope equilibrium while they were restrained in a Bollman cage : $3.46 \pm 0.28$ p. 100 of the fotal radioactivity extracted from the digestive tract and the feces. $88 \pm 4.6$ p. 100 of the radioactivity was recovered in the fractions corresponding to the pool. The values of the pool measured by the two techniques were equal : $48.5 \pm 3.17 \mu$ moles p. 100 of body weight with the WO technique and $48.5 \pm 1.60$ with the CIE method. The values of the daily basal biosynthesis established by the WO technique did not differ from those of the daily fecal excretion found by the CIE method : $17.9 \pm 1.34$ and $19.5 \pm 1.3 \mu$ moles, respectively, per $100 \mathrm{~g}$ of body weight.

Table 1 compares previous results obtained by applying the CIE method to those found with the present WO technique in rats fed the St.Pa.I., St.L.Pa.I., St.Pel.Au and St.L.Pel.Au. diets. The mean values of the pool determined by the WO technique were 
80 p. 100 of those obtained by the CIE method and remained very close to that mean percentage.

\section{TABLE 1}

Comparison between bile salt pool, daily basal biosynthesis and fecal excretion, using the cholesterol isotope equilibrium method (CIE) and the washout technique (WO) in rats different diets

\begin{tabular}{|c|c|c|c|c|c|c|}
\hline \multirow{2}{*}{$\operatorname{Diet}\left({ }^{(1}\right)$} & \multicolumn{3}{|c|}{ Bile salt pool ( $\left.{ }^{2}\right)$} & \multirow{2}{*}{$\begin{array}{c}\begin{array}{c}\text { Fecal } \\
\text { excretion }\left({ }^{3}\right)\end{array} \\
\text { CIE }\end{array}$} & \multicolumn{2}{|c|}{ Biosynthesis $\left({ }^{3}\right)$} \\
\hline & CIE & Wo & $\frac{\text { WO }}{C I E} \times 100$ & & Wo & $\frac{\text { WO }}{\text { CIE }} \times 100$ \\
\hline $\begin{array}{l}\text { St. Pa. I. . . . . } \\
\text { St. L. Pa. I. . . } \\
\text { St. Pel. Au. ... } \\
\text { St. L. Pel. Au. . } \\
\text { Mean ......... }\end{array}$ & $\begin{array}{l}56.0 \pm 1.1\left(^{4}\right) \\
61.3 \pm 1.8 \\
34.3 \pm 1.6 \\
52.7 \pm 3.5\end{array}$ & $\begin{array}{l}48.9 \pm 3.1 \\
49.9 \pm 1.8 \\
26.4 \pm 0.7 \\
37.8 \pm 3.7\end{array}$ & $\begin{array}{l}87 \\
81 \\
77 \\
72 \\
79.7\end{array}$ & $\begin{array}{l}10.2 \pm 0.3 \\
11.8 \pm 0.9 \\
12.9 \pm 0.9 \\
12.1 \pm 0.8\end{array}$ & $\begin{array}{l}15.2 \pm 0.7 \\
15.9 \pm 1.1 \\
7.8 \pm 1.1 \\
8.9 \pm 0.6\end{array}$ & $\begin{array}{c}150 \\
135 \\
60 \\
73 \\
104.5\end{array}$ \\
\hline
\end{tabular}

(1) St. $=$ Starch ; L. $=10$ p. 100 of lactose ; Su. = Sucrose ; Pel. = Pelleted ; Pa. = Paste ; l. = Irradiated ; Au. $=$ Autoclaved.

(2) $\mu$ moles per $100 \mathrm{~g}$ of body weight.

(3) $\mu$ moles per $100 \mathrm{~g}$ of body weight per day.

(4) Mean \pm standard deviation of the mean.

The mean values of basal bile salt biosynthesis, determined by the WO technique, were 105 p. 100 of those obtained by the CIE method, but varied from 150 p. 100 in the St.Pa.I. diet to 60 p. 100 in the St.Pel.Au. diet.

We concluded from these experiments that the WO technique provided a fairly good measurement of the total bile salt pool but that the estimation of biosynthesis was too irregular.

\section{TABLE 2}

Body weights, bile salt pools and daily secretion rates in rats fed different diets (Mean \pm standard deviation of the means of 6 rats)

\begin{tabular}{|c|c|c|c|c|}
\hline Diets $\left({ }^{1}\right)$ & $\underset{n^{\circ}}{\text { Group }}$ & $\begin{array}{c}\text { Body weight } \\
\text { (g) }\end{array}$ & $\begin{array}{l}\text { Bile salt pool } \\
\text { umoles } / 100 \mathrm{~g} \\
\text { body weight }\end{array}$ & $\begin{array}{c}\text { Bile salt secretion } \\
\text { umoles } / 100 \mathrm{~g} \\
\text { body weight } / 24 \mathrm{~h}\end{array}$ \\
\hline 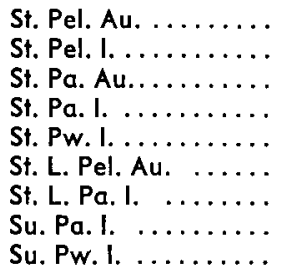 & $\begin{array}{l}1 \\
2 \\
3 \\
4 \\
5 \\
6 \\
7 \\
8 \\
9\end{array}$ & $\begin{array}{l}294 \pm 9.9 \\
279 \pm 3.1 \\
289 \pm 4.8 \\
280 \pm 4.2 \\
301 \pm 2.8 \\
277 \pm 7.2 \\
265 \pm 6.8 \\
262 \pm 6.8 \\
272 \pm 5.2\end{array}$ & $\begin{array}{l}26.4 \pm 0.7 \\
27.1 \pm 0.7 \\
24.8 \pm 1.8 \\
48.9 \pm 3.1 \\
33.3 \pm 2.0 \\
37.8 \pm 3.7 \\
49.9 \pm 2.0 \\
32.9 \pm 1.7 \\
35.1 \pm 2.0\end{array}$ & $\begin{array}{l}114 \pm 7.9 \\
119 \pm 4.5 \\
107 \pm 9.5 \\
187 \pm 4.5 \\
163 \pm 10.5 \\
175 \pm 18.6 \\
202 \pm 16.0 \\
159 \pm 9.9 \\
163 \pm 9.9\end{array}$ \\
\hline
\end{tabular}

(1) St. $=$ Starch ; L. $=10$ p. 100 of lactose ; Su. $=$ Sucrose ; Pel. $==$ Pelleted ; Pa. $=$ Paste Pw. = Dry powder ; Au. = Autoclaved ; I: = Irradiated. 
Effect of diet changes on bile salt pool and secretion rate. (The results are shown in table 2 and the statistical estimation in table 3 .)

TABLE 3

Values of $p$ determined by analysis of variance of bile salt pools and daily secretions in the experimental groups presented in table 2

\begin{tabular}{|c|c|c|c|}
\hline Groups no & Factors ( $\left.{ }^{1}\right)$ & Bile salt pools & Bile salt secretion \\
\hline $1,2,3,4$ & $\begin{array}{l}\text { Mode of sterilization : Au. vs. I. } \\
\text { Mode of preparation : Pel. vs. Pa. } \\
\text { Interaction }\end{array}$ & $\begin{array}{l}<0.001 \\
<0.001 \\
<0.001\end{array}$ & $\begin{array}{l}<0,001 \\
<0.005 \\
<0.001\end{array}$ \\
\hline $2,4,5$ & $\begin{array}{l}\text { Mode of preparation } \\
\text { Pw. vs. Pel. } \\
\text { Pa. vs. Pw. } \\
\text { Pa. vs. Pel. }\end{array}$ & $\begin{array}{l}<0.001 \\
<0.05 \\
<0.001 \\
<0.001\end{array}$ & $\begin{array}{l}<0.001 \\
<0.001 \\
<0.001 \\
<0.001\end{array}$ \\
\hline $4,5,8,9$ & $\begin{array}{l}\text { Composition St. vs. Su. } \\
\text { Mode of preparation : Pw. vs. Pa. } \\
\text { Interaction }\end{array}$ & $\begin{array}{l}<0.005 \\
<0.005 \\
<0.001\end{array}$ & N. S. \\
\hline $1,4,6,7$ & $\begin{array}{l}\text { Composition : effect of L } \\
\text { Mode of preparation : Pel. Au. vs. } \\
\text { Pw. I. } \\
\text { Interaction }\end{array}$ & $\begin{array}{l}\text { N. S. } \\
<0.001 \\
<0.025\end{array}$ & $\begin{array}{l}<0.025 \\
<0.0055 \\
\text { N.S. }\end{array}$ \\
\hline
\end{tabular}

(1) Abbreviations : as in table 2. Number of degrees of freedom of treatment $=1$ for all comparisons ; number of degrees of freedom of error $=15$ for comparisons between 4 groups and $=10$ for comparison between 3 groups.

A comparison of the first 4 groups (St.Pel.Au., St.Pel.I., St.Pa.Au., St.Pa.I.) confirmed the results obtained by the CIE method: the bile salt pool was much greater when the diet was irradiated than when it was autoclaved. But that result was only observed with the paste diet and not with the pelleted one (interaction). When the diet was given as a powder, the pool values ranged between those of the rats fed the pelleted diet and those of rats fed the paste diet (see comparison between groups 2, 4, 5 ; diets St.Pel.I., St.Pa.I., St.Pw.I.). When sucrose replaced starch, the pools showed similar values in the rats fed the powder diet, but adding water to the powder no longer increased the pool (significant interaction when groups 4, 5, 8, 9 were compared ; St.Pa.I., St.Pw.I., Su.Pa.I., Su.Pw.I. diets). When groups 1, 4, 6, 7 (St.Pel.Au., St.Pa.I., St.L.Pel.Au., St.L.Pa.I. diets) were compared, lactose effect was confirmed; the presence of 10 p. 100 of lactose in the diet did not modify the pool when the diet was irradiated, but increased it when the diet was autoclaved (interaction : $P<0.025$ ). In the previous study, such a result had already been observed in axenic rats, but was not significant in holoxenic ones.

The daily secretion rate varied as the pool, but the range in variation of these two physiological features was sometimes different. For instance, the addition of water to the starch diet did not induce a significant increase in rat secretion rate (see comparison between groups $4,5,8,9)$. The lowest interaction observed in the pools was no longer significant in the secretion rates (see comparison between $1,4,6,7)$. However, when the 54 values of the pool were plotted against the corresponding values of the 
daily secretion rate, a regression line was obtained : $r=0.74, P<0.01, y=3 x+51$ where $y$ is the daily secretion rate and $x$ the pool, both values being expressed in umoles per $100 \mathrm{~g}$ of body weight (fig. 2).

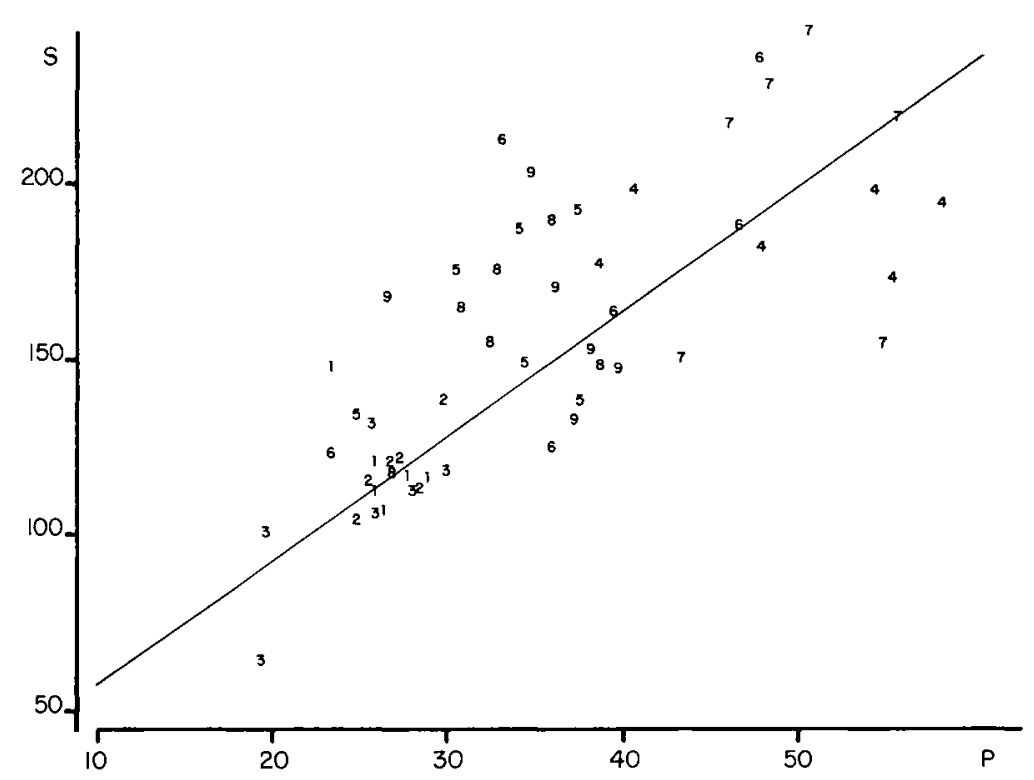

FIG. 2. - Relationship between bile salt pool size and daily secretion rate. Abscissa : $\mu$ moles of bile salt corresponding to pool (P); ordinate : $\mu$ moles of bile salt collected in fraction 1 . Each figure corresponds to a couple of individual values. Figures 1 to 9 designate the experimental groups as in table 2 .

\section{Discussion.}

A larger number of experiments is needed to determine the dietary components inducing variations in the BS pool. The WO rather than the CIE method was therefore used in this study because it was faster. The BS pool values obtained by these two methods were rather similar. Unfortunately, large discrepancies were observed when daily BS biosynthesis (determined by the WO technique) and fecal BS excretion (measured by the CIE method) were compared. No experimental proof has ever been presented that the "basal biosynthesis », defined by Mok, Perry and Dowling (1974), corresponds to the fecal excretion of intact rats. The same observation can be made concerning bile salt secretion rate which is liable to be disturbed by bile duct cannulation or by stress resulting from surgery and from restraint in a Bollman cage. However, as the rat has no gall bladder, it is likely that bile salt secretion in that animal depends mainly on intestinal absorption which is unmodified by the experimental conditions. Several techniques devised to study BS absorption have been carried out in similar conditions (Schiff, Small and Dietschy, 1972 ; Roy et al., 1979). The variation of BS absorption induced by the diet would therefore be similar in intact and operated rats.

Apart from the above-mentioned restrictions, the WO technique led to the fol- 
lowing conclusions : (1) the diet-induced variations in the intestinal BS pool, observed in the previous experiment, were related to the form (paste or pellef) in which the diet was offered ; dietary starch was requisite to that relationship ; (ii) the bile duct secretion rate of bile salts varied according to the intestinal BS pool.

As autoclaving the diet hydrolyzes the starch into smaller molecules and fransforms its structure, it is understandable that that effect on the diet ceased when the diet was autoclaved. It is more difficult to explain how the bile salt pool varied according to the form of the diet. As a relationship was seen between the transit time and the bile salt pool of the small intestine (Riottot et al., 1980), the form of the diet probably exerted an effect by changing the transit time. However, at present, we do not know how that action was accomplished. Incomplete hypotheses may be proposed. The velocity at which starch is hydrated could be the determining factor; that rate was slower when the diet was pelleted than when it was in powder form, while hydration was already achieved when the diet was ingested as a paste. The abundance of digestive secretion and the digestion rate might be changed, and those changes, in turn, affect transit time. A study of the effects of different starches of varying digestibility or of gel-forming substances such as pectin or agar-agar could help to clarify this matter. These substances have been studied as they modify cholesterol absorption or conversion into bile salts (Mathé ef al., 1977 ; Carroll ef al., 1978 ; Story and Kritchevsky, 1978), but their effects on the bile salt pool have not yet been investigated.

The second conclusion of this study is that the bile duct secretion rate of bile salts and, hence, their intestinal absorption rate, varied according to their intestinal pool. This relationship may be the result of passive BS absorption since that rate is proportional to BS concentration in this transport mechanism. The passive permeability coefficients of conjugated bile salts are low as compared to the parameters of active transport (Schiff, Small and Dietschy, 1972). However, several data suggest that the amount of conjugated bile salts passively absorbed by the whole intestine is larger than usually admitted : (i) the amounts of intestinal bile salts measured by the CIE or the WO technique are much higher than those determined by other methods some years ago (Van Belle, 1965), and (ii) passive absorption occurs throughout the intestinal tract. Moreover, passive absorption of free bile acids is very rapid, and in the caecum and large intestine most of the bile salts are deconjugated by bacterial cholyl glycine or taurine hydrolases. The active transport mechanism itself is also liable to vary (Caspary, 1973 ; Caspary and Creutzfeldt, 1975 ; Ostrower, Coan and Kern, 1974). Rats fed a commercial chow exhibited a higher sodium taurocholate absorption rate than rats fed a semi-synthetic diet (Riottot et al., 1975). As no difference was observed in the jejunal absorption rate, it would seem that the active ileum absorption rate was modified. This absorption rate was higher in rats fed the lactose autoclaved diet (St.L.Pel.Au.) than in those fed the lactose-free autoclaved diet (St.Pel.Au.) (Riottot et al., 1977).

The relationship between the intestinal pool of BS and their bile duct secretion rate agrees with the hypothesis that opposite variations in the BS pool and fecal BS excretion result from biosynthesis feedback regulation (Shefer et al., 1969). The values of the BS pool and biosynthesis are most likely regulated by simple mechanisms : when the BS pool increases because intestinal transit decreases, for instance, absorption increases and excretion consequently declines, but biosynthesis also drops due to 
feedback regulation. A new equilibrium between biosynthesis and secretion is established at a level which depends on these two functions.

Reçu en février 1980.
Accepté en mars 1980.

Résumé. Un aliment semi-synthétique, stérilisé par irradiation, est donné à des rats sous différentes formes : comprimés, poudre, pâte obtenue par mélange d'un poids égal d'eau et de poudre. La quantité de sels biliaires que renferme le tractus digestif des rats s'élève du premier au troisième cas. Cet effet de l'aliment disparaît quand, au lieu d'être irradié, il est autoclavé ou quand l'amidon est remplacé par du saccharose. La sécrétion cholédocienne de sels biliaires varie en fonction du contenu digestif en ces substances. Diverses hypothèses sont présentées pour expliquer cette relation entre l'aliment, le contenu en sels biliaires du tractus digestif et leur sécrétion cholédocienne.

\section{References}

CARROLL K. K., HAMILTON R. M. G., HAFF M. W., FALCONER A. D., 1978. Dietary fiber and cholesterol metabolism in rabbits and rats. Am. J. clin. Nutr., 31, S 203-S 207.

CASPARY W. F., 1973. Increase of active transport of conjugated bile salts in streptozotocin-diabetic rat small intestine. Gut, 14, 949-955.

CASPARY W. F., CREUTZFELDT W., 1975. Inhibition of bile salt absorption by blood-sugar lowering biguanides. Diabetologia, 11, 113-117.

MATHÉ D., LUTTON C., RAUTUREAU J., COSTE T., GOUFFIER E., SULPICE J. C., CHEVALLIER F., 1977. Effects of dietary fiber and salt mixtures on the cholesterol metabolism of rats. J. Nutr., 107, 466-474.

MOK H. Y. I., PERRY P. M., DOWLING R. H., 1974. The control of bile acid pool size : effect of jejunal reseccion and phenobarbitone on bile acid metabolism in the rat. Gut, 15, 247-253.

OSTROWER V. S., COAN P., KERN F., 1974. Effect of phenobarbital on intestinal cholic acid absorption in the rat. Gastroenterology, 67, 1162-1168.

RIOTTOT M., SACQUET E., MEJEAN C., LEPRINCE C., 1975. Effect of diet and microbial flora on intestinal absorption of sodium taurocholate in germ-free and conventional rats. Nutr. Rep. Int., 12, 1-7.

RIOTTOT M., SACQUET E., LEPRINCE C., MEJEAN C., 1977. Effect of dietary lactose on the absorption of sodium taurocholate in the rat ileum. Nutr. Rep. Int., 15, 421-427.

RIOTTOT M., SACQUET E., VILA J. P., LEPRINCE C., 1980. Relationship between small intestine transit and bile acid metabolism in axenic and holoxenic rats fed different diets. Reprod., Nutr., Dévelop., 20, 163-172.

ROY C. C., LefEBVRE D., BelaNGER G., CHARTRAND L., LePAGE G., Weber A., 1979. The effect of lipids on taurocholate absorption from the rat small intestine. Proc. Soc. exp. Biol. Med., 161, 105-110.

SACQUET E., van HEIJENOORT Y., RIOTTOT M., LEPRINCE C., 1975. Action de la flore microbienne du tractus digestif sur le métabolisme des acides biliaires chez le rat. Biochim. biophys. Acta, 380, 52-65.

SACQUET E., LEPRINCE C., RIOTTOT M., 1979. Effect of different modifications of a semi-synthetic diet on bile acid metabolism in axenic and holoxenic rats. Ann. Biol. anim. Bioch. Biophys., 19, 1677-1688.

SCHIFF E. R., SMALL N. C., DIETSCHY J., 1972. Characterization of the kinetics of the passive and active transport mechanisms for bile acid absorption in the small intestine and colon of the rat. J. clin. Invest., 51, 1351-1362.

SHEFER S., HAUSER S., BEKERSKY I., MOSBACH E., 1969. Feed-back regulation of bile acid biosynthesis in the rat. J. Lipid Res., 10, 646-655.

SNEDECOR G. W., COCHRAN W. G., 1957. Methodes statistiques, 6e éd. A.C.T.A., Paris, 379-424.

STEMPFEL R. S., SIDBURY J. B., 1964. Studies with hydroxysteroid dehydrogenases : A simplified method for the enzymatic estimation of 3- and 17-hydroxysteroids. J. clin. Endocr., 24, 367.

STORY J. A., KRITCHEVSKY D., 1978. Bile acid metabolism and fiber. Am. J. clin. Nutr., 31, S 203. S 207.

VAN BELLE H., 1965. Cholesterol, bile acids and atherosclerosis, North Holland, Publ. Co., 98-100. 